\title{
Chemical and Bioactive Metabolites of Humicola and Nigrospora Secondary Metabolites
}

\author{
Waill A. Elkhateeb*, Ghoson M. Daba \\ Chemistry of Natural and Microbial Products Department, National Research Centre, Dokki, Giza, 12622, Egypt.
}

*Corresponding Author: Wall A. Elkhateeb, Chemistry of Natural and Microbial Products Department, National Research Centre, Dokki, Giza, 12622, Egypt.

Received date: November 10, 2021; Accepted date: December 18, 2021; Published date: January 04, 2022

Citation: Waill A. Elkhateeb, Ghoson M. Daba (2022) Chemical and Bioactive Metabolites of Humicola and Nigrospora Secondary Metabolites. J. Pharmaceutics and Pharmacology Research. 5(1); DOI: 10.31579/2693-7247/058

Copyright: (C) 2022, Waill A. Elkhateeb, This is an open access article distributed under the Creative Commons Attribution License, which permits unrestricted use, distribution, and reproduction in any medium, provided the original work is properly cited.

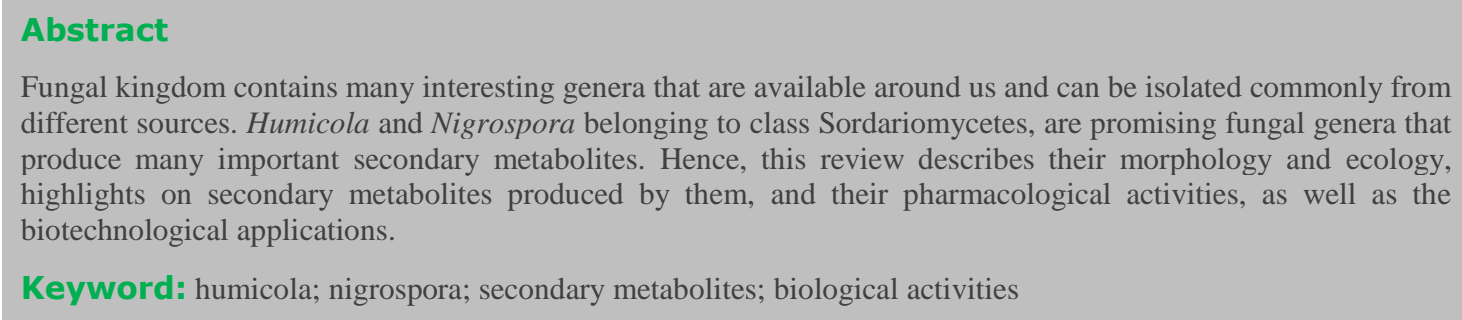

\section{Introduction}

Natural products have led to the excellent drugs for therapeutic purposes. Drugs of natural origin have been classified as original natural products, semi-synthetically from natural products or synthetic products. Natural products played important role in the drug discovery, particularly in the areas of cancer and infectious diseases [1]. Fungi are eukaryotic organisms that have the ability to synthesize an huge number of metabolites with a massive diversity of chemical structures and bioactivities. Fungal secondary metabolites are defined as small organic molecules that derived from biosynthetic pathways which are not required for maintenance and growth of the organism, and have specific rolls in environmental adaptation, and also contribute to the biological defence strategies [2].

The kingdom of fungi is the second largest group after insects and widely distributed in nature. Based on the observed ratio between flowering plant diversity and fungal diversity in countries where fungi have been sufficiently well studied, there are 1.5 million estimated fungal species [3]. They inhabit soils, the surface of mountain rocks, seawater and others [4]. Fungi produce a vast range of secondary metabolites [5-16], some of these metabolites are high-value products with pharmaceutical applications such as penicillins, a group of structurally related B-lactam antibiotics isolated from Penicillium chrysogenum. Several non-ß-lactam antibiotics are also produced by fungi such as griseofulvin. Griseofulvin which is isolated from Penicillium griseofulvum has been used for several years to treat dermatophyte infections of the skin, nails and hair of humans. [17].
Some valuable secondary metabolites produced commercially from fungi is Penicillins produced by Penicillium chrysogenum (Antibacterial), Cephalosporins produced by Acremonium chrysogenum (Antibacterial), Griseofulvin produced by Penicillium griseofulvum (Antifungal), Fusidin produced by Fusidium coccineum (Antibacterial), Ciclosporins produced by Tolypocladium spp. (Immunosuppressants), Zearalenone produced by Gibberella zeae (Cattle growth promoter), Gibberellins produced by Gibberella fujikuroi (Plant hormone), Claviceps purpurea produced, Ergot alkaloids and related compounds have many effects including: antimigraine, vasoconstriction, vasodilation, antihypertension, antiParkinson, psychiatric disorders [17].

Fungi generally and fungi Imperfecti especially have provided mankind with numerous important bioactive secondary metabolites such as $\beta$ lactam antibiotics, griseofulvin, cyclosporine A or lovastatin. Fungal species belonging to Class; Sordariomycetes are a wealthy source of enzymes with diverse biotechnological and industrial applications such as polysaccharide monooxygenase, L-methioninase, $\beta$-1,3-glucanase, laccase, dextranase, lipolytic, pectinolytic, amylolytic, chitinolytic, and proteolytic enzymes. Different classes of secondary metabolites have been reported from fungi belong to Class; Sordariomycetes, derived from various biosynthetic pathways such as alkaloids, polyketides, peptides, terpenes, and polyketide-amino acid hybrid secondary metabolites. These metabolites have attracted research interest due to their fascinating structural frameworks and bioactivities [2]. The current review represents the relevant information for Class; Sordariomycetes genera, Humicola and Nigrospora, secondary metabolites and their pharmacological activities, as well as the biotechnological applications. 


\section{Humicola and Nigrospora description and ecology}

The genus Humicola belonging to Phylum: Ascomycota; Order: Sordariales; Class: Sordariomycetes; Family: Chaetomiaceae. Colonies at first hyaline, darkening with age to be greyish, greyish brown or blackish brown; conidiophores indistinguishable or slightly indistinguishable from vegetative hyphae, unbranched or irregularly branched, colourless to pigmented, cylindric or slightly inflated; conidia (aleurioconidia) 1-celled solitary, terminal, globose, ovoid or pyriform, hyaline, pale to dark brown, smooth; phialoconidia sometimes produced in chains or in slimy heads, one-celled, smooth, colourless; intercalary chlamydospores sometimes produced. Most common species is Humicola fuscoatra and Humicola grisea. Humicola fuscoatra colonies attaining $2 \mathrm{Cm}$ after 7 days on malt extract agar at $25 \mathrm{C}$ on the other hand Humicola grisea colonies fast growing attaining $6.7 \mathrm{~cm}$ after 7 days on malt extract agar at
25C. Humicola is a filamentous dematiaceous fungus widely distributed in soil, and other sources (Figure, 1).

The genus Nigrospora belonging to Phylum: Ascomycota; Class: Sordariomycetes Order: Trichosphaeriales; Family: Trichosphaeriaceae. Nigrospora is a filamentous dematiaceous fungus widely distributed in soil, seeds and other source; conidiophores ins. Compare to Humicola, Nigrospora is differentiated from Humicola by its very black conidia that originate from hyaline, inflated conidiophores. Colonies at first white later brown to black, when the hyphae darken and shining conidia are profuse; conidiophores indistinguishable or slightly indistinguishable from the vegetative hyphae, branched, hyaline; conidia solitary, unicellular, globose or broadly elliptical, dorsiventrally flattened, shine, black, smooth. The most common Nigrospora spices is Nigrospora sphaerica. Colonies filling the whole plate after 2 days on malt extract agar at 25C (Figure, 2).

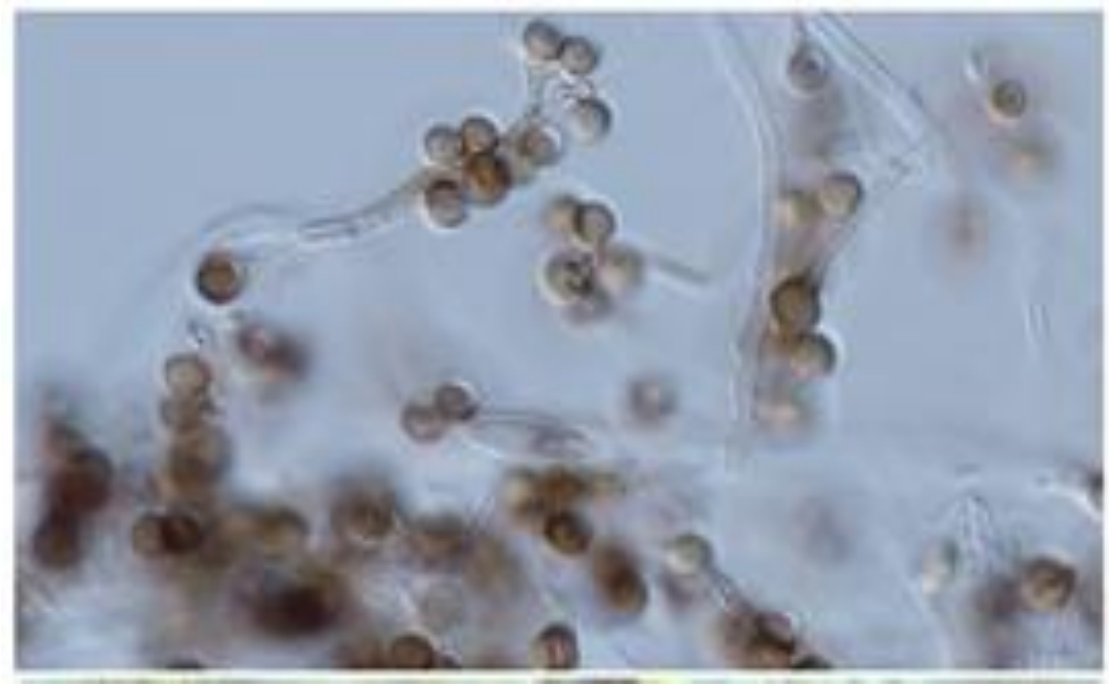

Figure (1). Humicola spp., hosted by: https://www.gene.affrc.go.jp/databases-micro_images_detail_en.php?id=21588.

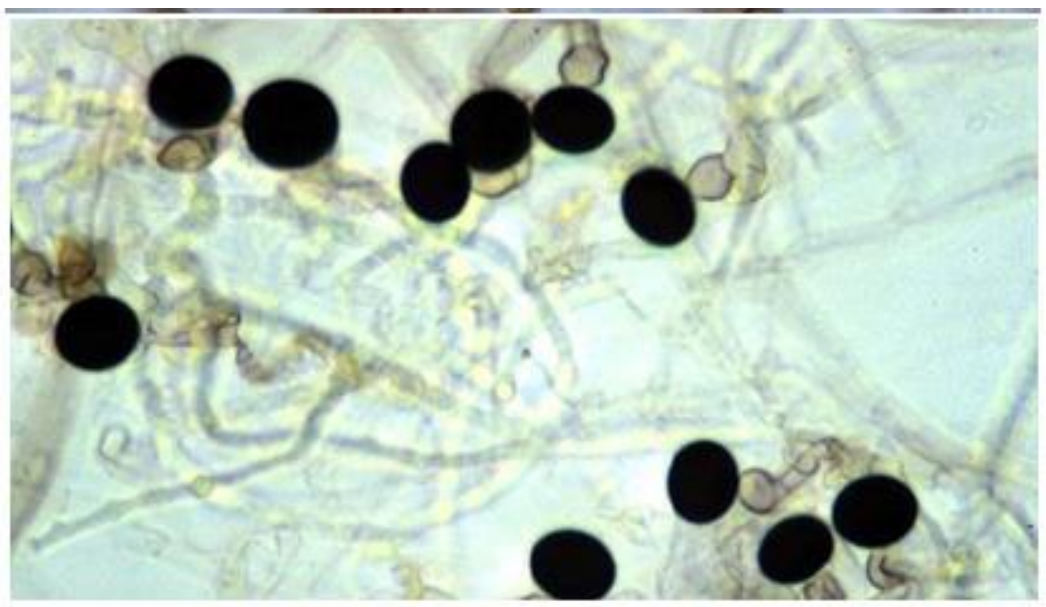

Figure (2). Nigrospora spp., hosted by: https://drfungus.org/knowledge-base/nigrospora-species/.

\section{Humicola and Nigrospora secondary metabolites as source of biologically active compounds}

Natural products especially antibiotics have been useful in our battles against infectious diseases, however, many antibiotics are used commercially, or are potentially useful, in medicine for activities other than their antibiotic action. Beside that antibiotics are used as antitumor agents, immunosuppressive agents, hypocholesterolemic agents, enzyme inhibitors, antimigraine agents, and antiparasitic agents. [18, 19]. New powerful antibiotics have been discovered and commercialized in recent years and others are in clinical testing [20]. Natural products from endophytes have gained wide attention from the research community due to their wide structural diversities with potential biological applications $[21,22]$.

Fungal metabolites in general and endophytic fungi especially are worthily taken into account as a pool of synthetically interesting and 
remarkably important new lead compounds for medical, agricultural, and chemical industries. Humicola species are known to have biotechnological and industrial potentials. Humicola genus (Family: Chaetomiaceae) is a source of unique and structurally diverse metabolites that have various bioactivities. Moreover, Humicola species attract substantial attention for their marked ability to produce thermostable enzymes with biotechnological and industrial importance [2]. Humicola species are known to have biotechnological and industrial potentials.

Many secondary metabolites were isolated from Humicola species (Fuscoatrol A; 11-epiterpestacin; $\beta$ nitropropionic acid which were isolated from the ethyl acetate extract of Humicola fuscoatra (Traaen) KMM 4629 mycelia that is associated with the Kuril colonial ascidium. Fuscoatrol A showed an antimicrobial activity against Staphylococcus aureus and Bacillus subtilis, and exerted cytotoxic effects on the developing eggs of sea urchin Strongylocentrotus intermedius, 11epiterpestacin exerted an antimicrobial activity against Staphylococcus aureus and $B$. subtilis only, while $\beta$-nitropropionic acid was active against S. aureus only [23]. Dimethyl terefthalate is another compound obtained from the dicloromethane extract of Humicola grisea var thermoidea [20]. This compound exerted antimicrobial activity against Escherichia coli, Kocuria rhizophila, Pseudomonas aeruginosa and Staphylococcus aureus. It should be mentioned that besides being obtained from petroleum, dimethyl tereftalate is used for production by biopolymer polytrimethylterefthalate (PTT), when polymerized with 1,3-propanediol [20]. Chemical analysis on the organic extract of Humicola fuscoatra NRRL 22980 revealed the presence of the triterpenoid glycoside, fuscoatroside which has antifungal activity against A. flavus. Also, 7deoxysterigmatocystin, sterigmatocystin, isosclerone, and decarestrictines A and I were also detected in this extract [24].

On the other hand, species of the genus Nigrospora are producers of various secondary metabolites that have broad range of bioactivity including antibacterial and phytotoxic nigrosporins A and B [25], solanapyrones [26], derivatives of pyrone [27], taxol [28], nigrosporanenes, tyrosol, and cyclohexene derivatives [29], anthraquinones [30], isochromenes [31], alkaloids [32], and furanone analogues [33]. Griseofulvin, dechlorogriseofulvin, 8-dihydroramulosin, and mullein were detected in the liquid cultures of Nigrospora sp. LLGLM003 which was isolated from the medicinal plant, Moringa oleifera [34]. Griseofulvin exerted In vitro antifungal activity against 8 plant pathogenic fungi. Dechlorogriseofulvin and mellein exhibited only weak antifungal activities, while 8-dihydroramulosin displayed no antifungal activities [34]. Many metabolites were extracted from Nigrospora sp. MA75 which was isolated from Pongamia pinnata such as 2,3-didehydro-19 $\alpha$-hydroxy-14-epicochlioquinone $\mathrm{B}$; two new griseofulvin derivatives (6-O-desmethyldechlorogriseofulvin; and 6'hydroxygriseofulvin); dechlorogriseofulvin; griseophenone C; tetrahydrobostrycin; 4- deoxytetrahydrobostrycin; 3,6,8-trihydroxy-1methylxanthon; and griseofulvin. Griseophenone $\mathrm{C}$ and 2,3-didehydro$19 \alpha$-hydroxy-14-epicochlioquinone B exhibited antibacterial activities toward five tested bacterial strains, while tetrahydrobostrycin; 4deoxytetrahydrobostrycin; and 3,6,8-trihydroxy-1-methylxanthon selectively inhibited MRSA, Escherichia coli, and Staphylococcus epidermidis. Griseofulvin showed moderate activity against $V$. mali and S. solani. Furthermore, 2,3-didehydro-19 $\alpha$-hydroxy-14epicochlioquinone B potently inhibited the growth of MCF-7, SW1990, and SMMC7721 tumour cell lines [35]. Ramesha et al., [22], reported the genus Nigrospora produce bioactive secondary metabolites, nigrosporolides, phomalactone [36], nigrosporins, lactones, epoxydons [37], diterpenes, diketopiperazines, lactones, nigrosporolides, and pyrones and these metabolites showing a broad spectrum of antimicrobial activity against human and phytopathogenic bacteria and fungi.
Nigrospora oryzae was isolated as an endophytic fungus from the leaves of Coccinia grandis, a popular medicinal plant used to control diabetes. Fermentation of the fungus in potato dextrose broth and chromatographic purification of the ethyl acetate extracts of the broth and mycelium yielded two phenazine secondary metabolites, which were identified as phenazine-1-carboxylic acid and phenazine-1-carboxamide. Phenazine1-carboxamide, isolated in high yield, showed strong antifungal activity against the plant pathogen Cladosporium cladosporioides. These phenazines have never been isolated from any fungal source. Antifungal activity of phenazine-1-carboxamide against Cladosporium cladosporioides is reported for the first time by Thanabalasingam et al., [38]. Species of Nigrospora harbor a great potential in bioactive secondary metabolite production. Nigrospora sphaerica is a rich source of secondary metabolites such as bioactive compounds with antileukemic (tested on HL60 and K562 cell lines), antileishmanial, and antifungal activities [39]. A new hydroanthraquinone derivative and new azaphilones produced by Nigrospora sp. YE3033 was reported to be successful in inhibiting influenza viral strain of A/Puerto Rico/8/34 (H1N1) [40].

\section{Conclusion}

Humicola and Nigrospora is an filamentous fungi belonging to Ascomycota division. Besides that, Humicola and Nigrospora Sp. are known for their capability of producing various biologically active compounds with medical applications as, antibacterial, and tumours. The aim of this review is to highlight the diversity of compounds produced by the genera Humicola and Nigrospora and pointing out their medical and other biological activities. Many researches performed on Humicola and Nigrospora, which called fungi Imperfecti, resulted in discovery of new metabolites or pointing to a possible application, which made Humicola and Nigrospora species potential source of pharmaceuticals and attracted attention for further investigations of their biological activities.

\section{References}

1. Cragg GM, Newman DJ. (2013). Natural products: a continuing source of novel drug leads. Biochimica et Biophysica Acta (BBA)-General Subjects, 1830(6): 3670-3695.

2. Ibrahim SR, Mohamed SG, Sindi IA, Mohamed GA. (2021). Biologically active secondary metabolites and biotechnological applications of species of the family Chaetomiaceae (Sordariales): an updated review from 2016 to 2021. Mycological Progress, 20(5): 595-639.

3. Hawksworth DL. (2001). The magnitude of fungal diversity: the 1.5 million species estimate revisited. Mycol. Res. 105(12): 14221432.

4. Feofilova EP. (2001) The Kingdom Fungi: Heterogeneity of physiological and biochemical properties and relationships with plants, animals and prokaryotes (review). Appl. Biochem. Microbiol. 37(2): 141-155.

5. Elkhateeb WA, Daba GM. (2018) Where to Find? A Report for Some Terrestrial Fungal Isolates, and Selected Applications Using Fungal Secondary Metabolites. Biomed Journal Science \&Technology Research; 4(4): 1-4.

6. Elkhateeb WA, Daba GM. (2019) The amazing potential of fungi in human life. ARC J. Pharma. Sci. AJPS, 5(3): 12-16.

1. 7. Elkhateeb WA, Daba GM. (2019). Epicoccum species as potent factories for the production of compounds of industrial, medical, and biological control applications. Biomedical Journal of Scientific and Technical Research, 14: 10616-10620.

7. Elkhateeb WA, Daba GM. (2019). Myrothecium as promising model for biotechnological applications, potentials and challenges. J. Sci. Res, 16: 12126-12131. 
8. Daba GM, Mostafa FA, Elkhateeb WA. (2021) The ancient koji mold (Aspergillus oryzae) as a modern biotechnological tool. Bioresources and Bioprocessing, 8(1): 1-17.

9. Daba GM, Elkhateeb WA, Thomas PW. (2018) This era of biotechnological tools: an insight into endophytic mycobiota. Egyptian Pharmaceu J, 17(3): 121-128.

10. Elkhateeb WA, EL-Ghwas DE, AL Kolaibe AG, Akram M, Daba GM (2021). Yeast the Present and Future Cell Facture. Open Access Journal of Mycology \& Mycological Sciences, 4(2): 1-5.

11. Elkhateeb WA, Elnahas MO, Daba GM, Zohri AN. (2021). Biotechnology and Environmental applications of Trichoderma spp. Research Journal of Pharmacognosy and Phytochemistry, 13(3): 149-157.

12. Elkhateeb WA, Kolaibe AG, Daba GM. (2021). Cochliobolus, Drechslera, Bipolaris, Curvularia different nomenclature for one potent fungus. Journal of Pharmaceutics and Pharmacology Research, 4(1): 1-6.

13. Elkhateeb WA, Kolaibe AG, Elnahas MO, Daba GM. (2021) Highlights on Chaetomium morphology, secondary metabolites and biological activates. Journal of Pharmaceutics and Pharmacology Research, 4(1): 1-5.

14. Elkhateeb WA. (2005). Some mycological, phytopathological and physiological studies on mycobiota of selected newly reclaimed soils in Assiut Governorate, Egypt (M. Sc. Thesis, Faculty of Science, Assuit University, Egypt. 2005; p 238.

15. Elkhateeb WA, Zohri AA, Mazen M, Hashem M, Daba GM. (2016). Investigation of diversity of endophytic, phylloplane and phyllosphere mycobiota isolated from different cultivated plants in new reclaimed soil, Upper Egypt with potential biological applications, Inter J MediPharm Res, 2(1): 23-31.

16. Deacon JW. (2006) Fungal spores, spore dormancy, and spore dispersal, p 184-212. Fungal biology, 4th ed. Blackwell Publishing, Oxford, United Kingdom.

17. Demain AL. (1999) Pharmaceutically active secondary metabolites of microorganisms. Applied microbiology and biotechnology, 52(4): 455-463.

18. Demain AL. (2009) Antibiotics: natural products essential to human health. Medicinal research reviews, 29(6): 821-842.

19. Andrioli W, Jorge JA, Bastos JK. (2008) Phenolic Metabolites from Humicola grisea var. thermoidea. Planta Medica, 74(03): P73.

20. Mohana NC, Rao HY, Rakshith D, Mithun PR, Nuthan BR, Satish S (2018) Omics based approach for biodiscovery of microbial natural products in antibiotic resistance era. J Genetic Eng Biotechnol 16(1):1-8.

21. Ramesha KP, Mohana NC, Nuthan BR, Rakshith D, Satish S. (2020) Antimicrobial metabolite profiling of Nigrospora sphaerica from Adiantum philippense L. Journal of Genetic Engineering and Biotechnology, 18(1): 1-9.

22. Smetanina OF, Kuznetsova TA, Gerasimenko AV, Kalinovsky AI, Pivkin MV, Dmitrenok PC, Elyakov GB. (2004) Metabolites of the marine fungus Humicola fuscoatra KMM 4629. Russian chemical bulletin, 53(11): 2643-2646.

23. Joshi BK, Gloer JB, Wicklow DT. (2002) Bioactive natural products from a sclerotium-colonizing isolate of Humicola fuscoatra. Journal of Natural Products, 65(11): 1734-1737.

24. Tanaka M, Fukushima T, Tsujino Y, Fujimori T. (1997). Nigrosporins $\mathrm{A}$ and $\mathrm{B}$, new phytotoxic and antibacterial metabolites produced by a fungus Nigrospora oryzae. Bioscience, biotechnology, and biochemistry, 61(11): 1848-1852.

25. Wu SH, Chen YW, Shao SC, Wang LD, Yu Y, et al. (2009) Two new solanapyrone analogues from the endophytic fungus Nigrospora sp. YB-141 of Azadirachta indica. Chem Biodivers 6: 79-85.

26. Trisuwan K, Rukachaisirikul V, Sukpondma Y, Preedanon S, Phongpaichit S, Sakayaroj J. (2009) Pyrone derivatives from the marine-derived fungus Nigrospora sp. PSUF18. Phytochemistry 70: 554-557.

27. Ruiz-Sanchez J, Flores-Bustamante ZR, Dendooven L, FavelaTorres E, Soca-Chafre G, Galindez-Mayer J, Flores-Cotera LB. (2010) A comparative study of Taxol production in liquid and solid-state fermentation with Nigrospora sp. a fungus. J Appl Microbiol 109, 2144-2150.

28. Rukachaisirikul V, Khamthong N, Sukpondma Y, Phongpaichit S, Hutadilok-Towatana N., Graidist P, Kirtikara K. (2010). Cyclohexene, diketopiperazine, lactone and phenol derivatives from the sea fan-derived fungi Nigrospora sp. PSU-F11 and PSUF12. Archives of pharmacal research, 33(3): 375-380.

29. Chen H, Zhu X, Zhong LL, Yang B, Li J, Wu JH, et al. (2012). Synthesis and antitumor activities of derivatives of the marine mangrove fungal metabolite deoxybostrycin. Mar Drugs 10: 2715-2728.

30. Metwaly AM, Kadry HA, El-Hela AA, Mohammad AI, Ma G, Cutler SJ, Ross S. (2014) Nigrosphaerin A a new isochromene derivative from the endophytic fungus Nigrospora sphaerica. Phytochem Lett 7, 1-5.

31. Dong JJ, Bao J, Zhang XY, Xu XY, Nong XH, Qi SH. (2014) Alkaloids and citrinins from marine-derived fungus Nigrospora oryzae SCSGAF 0111. Tetrahedron Lett 55: 2749-2753.

32. Zhang H, Deng Z, Guo Z, Tu X, Wang J, Zou K. (2014). Pestalafuranones F-J, five new furanone analogues from the endophytic fungus Nigrosporasp. BM2. Molecules 19, 819-825.

33. Zhao JH, Zhang YL, Wang LW, Wang JY, Zhang CL. (2012) Bioactive secondary metabolites from Nigrospora sp. LLGLM003, an endophytic fungus of the medicinal plant Moringa oleifera Lam. World Journal of Microbiology and Biotechnology, 28(5): 2107-2112.

34. Shang Z, Li XM, Li C, Wang BG. (2012). Diverse Secondary Metabolites Produced by Marine-Derived Fungus Nigrospora sp. MA75 on Various Culture Media. Chemistry \& biodiversity, 9(7): 1338-1348.

35. Kim J-C, Choi GJ, Park J-H, Kim HT, Cho KY (2001) Activity against plant pathogenic fungi of phomalactone isolated from Nigrospora sphaerica. Pest Manag Sci 57(6):554-559.

36. Trisuwan K, Rukachaisirikul V, Sukpondma Y, Preedanon S, Phongpaichit S, Rungjindamai N, Sakayaroj J (2008) Epoxydons and a pyrone from the marine-derived fungus Nigrospora sp. PSU-F5. J Nat Prod 71(8):1323-1326.

37. Thanabalasingam D, Kumar NS, Jayasinghe L, Fujimoto Y. (2015). Endophytic Fungus Nigrospora oryzae from a Medicinal plant Coccinia grandis, a High Yielding New Source of Phenazine-1-carboxamide. Natural communications, 10(10): 1659-1660.

38. Hao Y, Aluthmuhandiram JV, Chethana KT, Manawasinghe IS, Li X, Liu M, Zhang W. (2020). Nigrospora species associated with various hosts from Shandong Peninsula, China. Microbiology, 48(3): 169-183.

39. Zhang SP, Huang R, Li F, Wei HX, Fang XW, Xie XS, He J. (2016) Antiviral anthraquinones and azaphilones produced by an endophytic fungus Nigrospora sp. from Aconitum carmichaeli. Fitoterapia . 112: 85-89. 